\title{
Fundamentos da filosofia Ubuntu: afroperspectivas e o humanismo africano
}

\author{
Fundamentals of philosophy Ubuntu: afroperspectivas and african humanism
}

CAVALCANTE, Kellison Lima Cavalcante. Mestre/Licenciado em Filosofia

Instituto Federal de Educação, Ciência e Tecnologia do Sertão Pernambucano - Campus Petrolina.

Rua Maria Luiza de Araújo Gomes Cabral, S/N, João de Deus - Petrolina - Pernambuco - Brasil. CEP:

56.316-686 / Telefone: (87) 2101-4300 / E-mail: kellison.cavalcante@ifsertao-pe.edu.br

\section{RESUMO}

A palavra Ubuntu tem origem nos idiomas zulu e xhosa do sul do continente africano e tem como significado a humanidade para todos. Nesse sentido, a Filosofia Ubuntu fundamenta-se em uma ética da coletividade, representada principalmente pela convivência harmoniosa com o outro e baseada na categoria do "nós", como membro integrante de um todo social. Dessa forma, este trabalho tem como objetivo refletir sobre os fundamentos da Filosofia Ubuntu, considerando-a como uma das várias correntes da filosofia africana. Assim, o estudo foi desenvolvido por meio uma pesquisa bibliográfica, requerendo o uso do método explicativo. A Filosofia Ubuntu resgata a essência de ser uma pessoa com consciência de que é parte de algo maior e coletivo. Para isso, de acordo com os fundamentos da Filosofia Ubuntu, somos pessoas por meio de outras pessoas e que não podemos ser plenamente humanos sozinhos, sendo feitos para a interdependência. Nesse contexto, fundamenta-se nas relações entre o divino, a comunidade e a natureza. No entanto,, a Filosofia Ubuntu procura resgatar o conceito de Comum para alcançar a democracia, ou seja, uma multiplicidade de singularidades. Para tal, tem a igualdade como um princípio fundamental e condicional para a existência do outro.

Palavras-chave: Filosofia Africana, Ubuntu, Humanidade.

\begin{abstract}
The word Ubuntu comes from the Zulu and Xhosa languages of the southern African continent and means humanity for all. In this sense, the Ubuntu Philosophy is based on an ethics of collectivity, represented mainly by harmonious coexistence with the other and based on the category of "we", as an integral member of a social whole. Thus, this work aims to reflect on the fundamentals of Ubuntu Philosophy, considering it as one of the several currents of African philosophy. Thus, it will be developed through a bibliographic search, requiring the use of the explanatory method. The Ubuntu Philosophy rescues the essence of being a person with the awareness that he is part of something bigger and collective. For that, according to the fundamentals of the Ubuntu Philosophy, we are people through other people and that we cannot be fully human alone, being made for interdependence. In this context, it is based on the relationships between the divine, the community and nature. However, the Ubuntu Philosophy seeks to rescue the concept of the Common to achieve democracy, that is, a multiplicity of singularities. For that, it has equality as a fundamental and conditional principle for the existence of the other.
\end{abstract}

Keywords: African Philosophy, Ubuntu, Humanity. 
CAVALCANTE, K. L. (2020)

Fundamentos da filosofia Ubuntu: afroperspectivas e o humanismo africano

\section{Introdução}

A filosofia aparece como uma atividade do pensamento em busca da compreensão do mundo e de verdades encontradas na racionalidade humana de forma holística e integradora. Assim, a filosofia permeia a construção de novas conexões em busca de novos territórios do conhecimento, trazendo manifestações aos distintos modos de existência do ser. Dessa forma, é possível visualizar a filosofia a partir de diferentes perspectivas éticas que se originam mediante a experimentação e de uma geo-ética.

$\mathrm{Na}$ contemporaneidade, a filosofia é produzida e disseminada em todos os continentes, de forma relevante e com pensamentos sofisticados sobre o mundo e os mais diversos questionamentos das verdades. Assim, a filosofia africana, em detrimento do pensamento eurocêntrico e norteamericano, apresenta-se a partir de uma preocupação com o outro e da existência humana de forma coletiva.

Deleuze e Guattari (2010) ressaltam que a filosofia é uma geofilosofia, protegendo o pensamento do caos, onde a diversificação consiste na afirmação da potência do meio. Assim, defendem que o pensamento precisa ter novos olhares e movimentos, contemplando a criação de novos conceitos.

Esses pensadores defendem a necessidade do encontro da filosofia e o plano de imanência do pensamento em conceituação de uma geo-filosofia (DELEUZE E GUATTARI (2010). Essa conceituação constitui-se dando ênfase na territorialização, desterritorialização e reterritorialização, significando e representando um movimento para fora de si e ao encontro ou até mesmo de desencontro de novas formas de pensar.

Nesse sentido, a ética Ubuntu, com origem nos povos sul-africanos zulu e xhosa, pode ser compreendida a partir do pensamento de uma humanidade para todos. Para Nascimento (2016), a palavra Ubuntu é a denominação de uma espécie de "Filosofia do Nós", significando uma ética coletiva com a finalidade de conectar as pessoas com a vida, com a natureza, com o divino e com as outras pessoas de forma comunitária, em um plano de imanência onde todas a forças se unem e se cruzam. A filosofia Ubuntu no pensamento africano apresenta uma perspectiva da construção coletiva do pensamento e da racionalidade humana, tornando o ser como um potencial territorializante e desterritorializante.

Para Noguera (2012), o termo Ubuntu pode ser compreendido como uma ética que é comum a todas as pessoas, proporcionando um ritmo harmonioso dos fluxos na busca do reconhecimento e valorização do território. Dessa forma, as filosofias africanas preocupam-se no entendimento da realidade diante de uma articulação coletiva, permitindo a formação de novos encontros e do retorno para o seu solo absoluto, onde todos se encontram. Essa articulação é compreendida por Tempels (2013) como um conjunto de energias e forças vitais.

De acordo com Nascimento (2016) os princípios fundamentais da ética Ubuntu são norteados pela preocupação com o outro, com a solidariedade, com a partilha e com a vida em comunidade. Assim, uma geoética e uma geofilosofia se apresentam nos fundamentos da filosofia ubuntu, trazendo 
o ser em sua existência como a essência de uma coletividade, explicando que uma pessoa não pode ser plenamente humana sozinha.

A partir da discussão da geofilosofia proposta por Deleuze e Guattari (2010), esse trabalho é construído pela proposta de estudo e conhecimento dos pensamentos e filosofias afroperspectivistas para as relações das pessoas consigo e com as outras de forma coletiva e integradora, baseando-se nos fundamentos e conceitos da filosofia ubuntu. Para Noguera (2012), o termo afroperspectivista tem um sentido simples, o conjunto de pontos de vista, estratégias, sistemas e modos de pensar e viver de matrizes africanas.

Nascimento e Botelho (2010) ressaltam a relevância do estudo da filosofia ubuntu com a possibilidade de oferecer conceitos que permitem compreender, pela história da filosofia, realidades em constante movimento. Dessa forma, esse trabalho tem como objetivo discutir os fundamentos da ética ubuntu no pensamento africano e as suas contribuições no pensamento contemporâneo de forma descentralizada. Foramoram observadas as principais reflexões e contribuições afrodiaspóricas produzidas na perspectiva de investigação sobre o pensamento africano e os seus mais relevantes desdobramentos.

\section{Os Fundamentos da Filosofia Ubuntu}

De acordo com Ramose (2001) a palavra ubuntu origina-se da combinação dos termos ubu e ntu. Ainda para Ramose (2001), o prefixo ubu contempla a ideia do Ser em seu modo dinâmico, integral, anterior às manifestações particulares ou modos de existência, em um constante movimento, e o sufixo ntu indica toda manifestação particular, os modos distintos de existência. Nesse sentido, a compreensão da palavra ubuntu nos permite indicar tudo o que está em nosso convívio, tudo aquilo que temos em comum em uma realidade integradora de tudo o que está se transformando.

Filosoficamente, é melhor aproximar-se deste termo como uma palavra hifenizada, ubu-ntu. Ubuntu é atualmente duas palavras em uma. Consiste no prefixo ubu- e na raiz ntu. Ubu evoca a ideia da existência, em geral. Abrindo-se à existência antes de manifestar a si mesmo na forma concreta ou no modo de existência de uma entidade particular. Ubu, aberto à existência, é sempre orientado para um desdobramento, que é uma manifestação concreta, incessantemente contínua, através de formas particulares e modos de ser. Neste sentido, ubu é sempre orientado para um ntu. (RAMOSE, 1999, p. 50).

Ainda nessa perspectiva, Ramose (1999) explica que:

Ubuntu é a raiz da filosofia africana. A existência do africano no universo é inseparavelmente ancorada sobre ubuntu. Semelhantemente, a árvore de conhecimento africano deriva do ubuntu com o qual é conectado indivisivelmente. Ubuntu é, então, como uma fonte fluindo ontologia e epistemologia africana. Se estas últimas forem as bases da filosofia, então a filosofia africana pode ser estabelecida em e através do ubuntu. (p. 1). 
CAVALCANTE, K. L. (2020)

Fundamentos da filosofia Ubuntu: afroperspectivas e o humanismo africano

Nesse sentido, a filosofia ubuntu constitui um dos fundamentos das filosofias africanas, a representatividade do povo bantu. Para Eze (2001) demonstra a representatividade de um modelo de humanidade, de cultura e da história de uma comunidade.

Dee acordo com Ramose (1999) a ética da filosofia ubuntu compreende a existência do ser africano e dos grupos étnicos africanos, trazendo em discussão o posicionamento moral em relação a comunidade local e ao universo. Para isso, a base da filosofia ubuntu relaciona os fundamentos de uma ética integradora, trazendo os conceitos de humanidade e comunidade.

Sobre a ética da filosofia ubuntu, Saraiva (2019) explica que:

Esta dinâmica da linguagem consegue produzir uma comunicação abrangente sobre a totalidade da realidade, isto faz com que a ética Ubuntu se concentre em uma conexão de relações de pessoas consigo e com outras pessoas dentro da comunidade por meio do Ntu que "é o denominador comum que aparece em todos os seres. (p. 101)

Com isso, o ser em comunidade pode ser compreendido a partir de sua integração com sua comunidade, conectando relações. Assim, Saraiva (2019) explica que o conhecimento sobre a ética ubuntu possibilita experimentar a nossa experiência humana, não de maneira individual, mas em grau comunitário, sempre se projetando em um espaço de compreensão social. Essa perspectiva contempla o pensamento integrador da ética ubuntu, trazendo o ser e sua relação social em sua comunidade. Por isso, Ondó (2001) ressalta que o próprio ser é definido por sua natureza e função.

Dessa forma, a filosofia ubuntu pode ser explicada como um pensamento em constante movimento a partir de uma maneira de viver e existir com as outras pessoas. Noguera (2012) explica que a filosofia ubuntu trata de uma existência comunitária antirracista e ploicêntrica. Por isso, em muitos estudos é possível encontrar a associação de ubuntu com a tradução de "humanismo. Justificando-se pela busca de compreensão dos relacionamentos das pessoas consigo e com as outras.

A formação da palavra ubuntu remete a uma ideia de articulação entre a existência do ser e as diversas possibilidades de conhecê-lo em sua essência e formas de convivência. Para Nascimento (2016), a existência relacionada a ubuntu está sempre em um processo de desdobramento e manifestação, dinâmico e incessante. Ainda para Nascimento (2016), tal manifestação está sempre à espreita de ser observada pelo existente concreto que expressa ubuntu, o coletivo da humanidade.

Para explicar a sua conceituação geofilosófica, Malomalo (2014) destaca que:

Do ponto de vista filosófico e antropológico, o ubuntu retrata a cosmovisão do mundo negro-africano. É o elemento central da filosofia africana, que concebe o mundo como uma teia de relações entre o divino (Oludumaré/Nzambi/Deus, Ancestrais/Orixás), a comunidade (mundo dos seres humanos) e a natureza (composta de seres animados e inanimados). Esse pensamento é vivenciado por todos os povos da África negra tradicional e é traduzido em todas as suas línguas... Como elemento da tradição africana, o ubuntu é reinterpretado ao longo da história política e cultural pelos africanos e suas diásporas. (p. 58)

Como elemento da tradição africana dos povos bantus, a filosofia ubuntu estabelece reflexões sobre a existência em comunidade e de interdependência na vida política, cultural e social. No 
CAVALCANTE, K. L. (2020)

Fundamentos da filosofia Ubuntu: afroperspectivas e o humanismo africano

pensamento ubuntu existe a necessidade do ser estar inserido em uma comunidade, com uma força vital voltada para si e para os demais.

Dessa forma, a filosofia ubuntu fundamenta-se no pensamento filosófico africano da coletividade e da integração dos elementos da natureza e da existência do ser. Nesse sentido, Cunha Júnior (2010) explica o pensamento africano como:

[...] formas filosóficas de refletir e ensinar e aprender sobre as relações dos seres da natureza, do cosmo e da existência humana, são filosofias pragmáticas da solução dos problemas da vida na terra, profundamente ligados ao existir e compor o equilíbrio de forças da continuidade saudável destas existências, sempre na dinâmica dos conflitos e das possibilidades de serem postas em equilíbrio. A contradição e a negociação. Os problemas da existência física e espiritual fundamentam-se nos da existência de uma totalidade que governa as gerações e que permite a continuidade dinâmica da vida pela interferência humana. São formas de pensar, tomadas dos mitos, dos provérbios, dos compromissos sociais que formam uma ética social, refletem, inscrevem [...], registrado na oralidade os condicionantes da existência humana, da formação social, das relações de poder e justiça, da continuidade da vida. A natureza como respeito profundo a vida. (p. 82).

Fundamentando-se na ancestralidade africana, a filosofia ubuntu preocupa-se fundamentalmente com o indivíduo, com a natureza e as suas relações entre si, havendo uma interdependência. Assim, cada ser consegue contribuir de forma coletiva e integradora na construção das relações. Dessa forma, a filosofia ubuntu, assim como a filosofia africana, é construída no plano da solidariedade, através da interação de todos. Um existindo por causa da existência do outro.

\section{Afroperspectivas sobre Ubuntu}

De acordo com Nascimento (2016) as filosofias africanas são plurais em sua vertente contemporânea que se constituiu como uma resposta ao eurocentrismo, bem como em outras perspectivas, as quais em níveis diferentes de diálogo com o pensamento ocidental, abordam problemas, instanciações e perspectivas distintas. Nesse sentido, tomando como base a relação feita por Kagame (2013) em que a partícula ntu, usado nas línguas bantas, corresponde ao ser da filosofia euro-americana, Nascimento (2016) ressalta que na filosofia ubuntu o ser é dinâmico, articulado, e que se manifesta na interdependência dos diversos existentes.

Nesse sentido, para Saraiva (2019) cada pessoa é a representatividade de uma parte da humanidade, trazendo suas formas de culturas e de sua própria história. Assim, a existência do ser, a partir da ética ubuntu, existe no sentido de humanidade e integradora da realidade da comunidade que é e que faz parte.

Conforme Nascimento (2017), a filosofia ubuntu é o espírito ou princípio filosófico fundamental da vida do povo africano, sendo um conceito que compõe o reconhecimento do ser humano consigo mesmo e com os outros, por uma indelével experiência entre os homens, mulheres e o mundo em uma harmonia universal. Dessa forma, Nascimento (2016) destaca que podemos entender 
CAVALCANTE, K. L. (2020)

Fundamentos da filosofia Ubuntu: afroperspectivas e o humanismo africano

o motivo pelo qual um dos principais esforços das filosofias africanas, e também da perspectiva ubuntu, é refazer a imagem, a representação dos povos africanos e, assim, refazer a imagem da própria humanidade e de suas diversas relações internas e com as outras instâncias da existência.

Castiano (2010) traz uma leitura da expressão de vida e da prática ética do ubuntu:

Ubu-ntu é a categoria epistemológica e ontológica fundamental no pensamento dos povos Bantu, expressando o ubu uma compreensão generalizada da realidade ontológica do Ser enquanto Ser, e o ntu assumindo formas e modos concretos de existência num processo contínuo (p.156).

Nesse sentido, a filosofia ubuntu caracteriza-se como um modo de vida para aqueles que buscam liberdade de forma indissociável dos valores humanos éticos, como observados nas lutas durante o regime segregacionista e racista do apartheid na África do Sul. Para Nascimento (2017) a prática ética do ubuntu representou a experiência da tradição filosófica do homem negro contra a violência na reconciliação política e na constituição de sujeitos. Dessa forma, de acordo com Nascimento (2012), a filosofia ubuntu mantém seus pressupostos afirmados a partir da cosmovisão histórica não meramente colonial.

Nessa perspectiva, Mudimbe (2013) ressalta que o ser em comunidade, no estudo ético da filosofia ubuntu, é compreendido como uma entidade natural e social. Assim, o contexto em que está inserido interfere na dinâmica e formação do ser, bem como na sua história. Por isso, Saraiva (2019) destaca que essa compreensão origina o sentimento de pertencimento de partilha das experiências de ser, estar e fazer no mundo.

Para Cunha Júnior (2010), na filosofia ubuntu temos a existência definida pela existência de outras existências. Dessa forma, o conceito de humanidade ganha valores nas relações estabelecidas com a finalidade de continuidade da solidariedade e das relações. Ressalta-se aqui , a existência do ser que depende da existência do outro, a partir do pensamento em comunidade.

Eu, nós, existimos porque você e os outros existem; tem um sentido colaborativo da existência humana (CUNHA JÚNIOR, 2010). Assim, Chaua (2014) destaca que no pensamento ubuntu o cônscio comigo e para com o outro se encontra em voga, promovendo encontros e reconhecimentos dos valores da humanidade. Dessa forma, os sentidos de humanitarismo são colocados no centro da discussão ética do ubuntu.

Nesse sentido, para Vasconcelos (2017) ubuntu aponta uma existência marcada pela convivência harmoniosa com o outro, traduzindo o respeito que se converte na valorização do humano e da natureza. A existência do ser na ética ubuntu situa-se por meio da relação com a natureza e com os outros em forma de comunidade.

Sobre isso, Ramose (2010) explica que em termos coletivos, o ubuntu se manifesta nos princípios da partilha, da preocupação e do cuidado mútuos, assim como da solidariedade. De acordo com o pensamento do filósofo sul-africano, em um sentido comum da filosofia, a partir do amor ao conhecimento, o pensamento ubuntu destaca a importância vital do "nós".

Para Louw (2010), compreende-se uma concepção ética mediante o pensamento ubuntu de que o ser existe por meio dos outros, em um sentido de cuidado e partilha. Evidencia-se o surgimento 
CAVALCANTE, K. L. (2020)

Fundamentos da filosofia Ubuntu: afroperspectivas e o humanismo africano

do aforismo africano de que uma pessoa é uma pessoa por meio de outras pessoas e o pensamento integrador das relações sociais em comunidade. Ainda no pensamento de Low (2010), em um sentido comum ou, se se preferir, secular, ubuntu significa simplesmente compaixão, calor humano, compreensão, respeito, cuidado, partilha, humanitarismo ou, em uma só palavra, amor. O conceito expresso pelo filósofo e psicólogo sul-africano consiste na constituição de comunidade como base do pensamento ubuntu, incluindo o sentido de humanidade por meio dos outros, onde ninguém está excluído.

Swanson (2010) admite o ubuntu como uma "alternativa ecopolítica" à globalização econômica neoliberal e que em suma podemos entender como uma forma ética de conhecer e de ser em comunidade. Para Swanson (2010), o pensamento ubuntu liga o indivíduo ao coletivo por meio daa "fraternidade" ou da "sororidade", contribuindo para as "fomas nativas de conhecer o ser". De e acordo com o pensamento dessa educadora sul-africana, o ubuntu traduz-se como uma forma de humanismo africano e um coletivo humano para com os outros, conhecendo o ser por sua pertença a um coletivo humano. Trazendo o sentido de união e de comunidade do pensamento ubuntu.

Nesse sentido, Malomalo (2010) explica que ubuntu é o elemento central da filosofia africana, que concebe o mundo como uma teia de relações entre o divino, a comunidade e a natureza. Dessa forma, as reflexões filosóficas do filósofo congolês a importância da compreensão do fundamento básico do pensamento ubuntu, em que o eu só existe porque nós existimos. E assim, o humanismo africano proporciona um grande senso de responsabilidade entre o equilíbrio cósmico, natural e social e a existência do ser.

\section{Conclusões}

A filosofia ubuntu representa um pensamento filosófico de origem dos povos bantus, das filosofias africanas e suas formas de conhecimento de humanidade, de cultura, de história e das formas de relacionamento social entre os povos. Quanto à ética ubuntu, acentua-se o conceito de humanidade em sua essência e seu modelo integrador do ser e de sua comunidade. A filosofia ubuntu compreende a concepção bantu da realidade da existência de seu povo em uma dinâmica e movimento da existência do ser em comunidade e de se importar com o outro.

Dessa forma, a partir da compreensão da filosofia ubuntu, a ética com base no respeito e na solidariedade consigo e com o outro constituem a essência do ser, fazer e estar em comunidade. Por isso, a filosofia ubuntu pode ser compreendida a partir dos preceitos de uma humanidade para com os outros e que eu sou porque nós somos. A existência e essência do ser são os fundamentos e preceitos do pensamento ubuntu de vida em comunidade. A partir dessa discussão, podemos compreender o pensamento ubuntu como uma filosofia africana do humanismo, pelas relações do ser e dos outros de forma coletiva.

Nesse sentido, o fundamento básico desse pensamento africano articula um respeito básico pelos outros, pela comunidade e pela integração do ser e de sua realidade. Descreve o sentido de 
CAVALCANTE, K. L. (2020)

Fundamentos da filosofia Ubuntu: afroperspectivas e o humanismo africano

humanidade e de ser com os outros. Como tal, o pensamento ubuntu oportuniza e valoriza as formas de pensamentos africanos, silenciados pelo eurocentrismo a partir de descolonização.

\section{Referências}

CASTIANO, J. P. Referenciais da filosofia africana: em busca da intersubjectivação. Maputo, Moçambique: Editora Ndjira, 2010.

CHAUA, R. Sobre África: questões, tradições e ubuntu. Pensando os ritos de iniciação em Moçambique. Revista Teias, v. 15. n. 35, p. 38-53, 2014.

CUNHA JUNIOR, H. Ntu. Revista Espaço Acadêmico, v. 9, n.108, maio, 2010.

DELEUZE, G.; GUATTARI, F. 0 que é a filosofia? 3. ed. Trad. Bento Prado Jr. e Alberto Alonso Muñoz. Rio de Janeiro: Editora 34, 2010.

EZE, E. C. Pensamiento africano: ética y política. Barcelona: Ed. Bellaterra, 2001.

KAGAME, A. La philosophie Bantu comparée. Paris: Presence Africaine, 2013.

LOUW, D. Ser por meio dos outros: o ubuntu como cuidado e partilha. Entrevista. Trad.: Luís Marcos Sander. Revista do Instituto Humanitas Unisinos, ed. 353, ano X, p. 5-7, 2010.

MALOMALO, B. "Eu só existo porque nós existimos": a ética Ubuntu. Entrevista. Trad.: Moisés Sbardelotto. Revista do Instituto Humanitas Unisinos, ed. 353, ano X, p. 19-22, 2010.

MALOMALO, B. Filosofia do Ubuntu: Valores civilizatórios das ações afirmativas para o desenvolvimento. Curitiba: CRV, 2014.

MUDIMBE, V. Y. A invenção de África. Gnose, filosofia e a ordem do conhecimento. Luanda: Edições Pedago, 2013.

NASCIMENTO, A. Ubuntu como fundamento. UJIMA - Revista de Estudos Culturais e Afrobrasileiros, n. 1, jun., 2016.

NASCIMENTO, C. E. G. A ética filosófica do Ubuntu na sala de aula: um debate sobre o racismo no futebol brasileiro. Revista Ideação, edição especial, p. 319-338, 2017. 
CAVALCANTE, K. L. (2020)

Fundamentos da filosofia Ubuntu: afroperspectivas e o humanismo africano

NASCIMENTO, W. F. Aproximações brasileiras às filosofias africanas: caminhos desde uma ontologia ubuntu. Prometeus, ano 9, n. 21, edição especial, p. 231-245, dez., 2016.

NASCIMENTO, W. F.; BOTELHO, D. Colonialidade e Educação. O currículo de filosofia brasileiro entre discursos coloniais. Revista Sul-Americana de Filosofia e Educação, n. 14, p. 66-89, maio/out., 2010.

NASCIMENTO, W. F. Outras vozes no ensino de filosofia: o pensamento africano e afro-brasileiro. Revista Sul-Americana de Filosofia e Educação, n. 18, p. 74-89, maio/out., 2012.

NOGUERA, R. Ubuntu como modo de existir: elementos gerais para uma ética afroperspectivista. Revista da ABPN, v. 3, n. 6, p. 147-150, fev., 2012.

ONDÓ, E. N. Síntesis sistemática de la filosofía africana. Barcelona. Edicionescarena, 2000.

RAMOSE, M. B. A importância vital do "Nós". Entrevista. Trad.: Luís Marcos Sander. Revista do Instituto Humanitas Unisinos, ed. 353, ano X, p. 8-9, 2010.

RAMOSE, M. B. African philosophy through ubuntu. Harare: Mond Books, 1999.

RAMOSE, M. B. An african perspective on justice and race. 2001. Disponível em: <https://them.polylog.org/3/frm-en.htm>. Acesso em: 21 set. 2019.

SARAIVA, L. A. F. O que e quem não é ubuntu: crítica ao "eu" dentro da filosofia ubuntu. Problemata: R. Intern. Fil., v. 10, n. 2, p. 93-110, 2019.

SWANSON, D. Ubuntu, uma "alternativa ecopolítica” à globalização econômica neoliberal. Entrevista. Trad.: Luís Marcos Sander. Revista do Instituto Humanitas Unisinos, ed. 353, ano X, p. 10-13, 2010.

TEMPELS, P. La Philosophie Bantoue. Paris: Presence Africaine, 2013.

VASCONCELOS, F. A. Filosofia ubuntu. Logeion: Filosofia da Informação, Rio de Janeiro, v. 3, n. 2, p. 100-112, mar./ago. 2017. 